\title{
The impact of high intensity care around birth on long-term neurodevelopmental outcomes
}

\author{
Corneliu Bolbocean ${ }^{1,2^{*}}$ and Michael Shevell ${ }^{3}$
}

\begin{abstract}
Background: An equitable and affordable healthcare system requires a constant search for the optimal way to deliver increasingly expensive neonatal care. Therefore, evaluating the impact of hospital intensity around birth on long-term health outcomes is necessary if we are to assess the value of high intensity neonatal care against its costs.

Methods: This study exploits uneven geographical distribution of high intensity birth hospitals across Canada to generate comparisons across similar Cerebral Palsy (CP) related births treated at hospitals with different intensities. We employ a rich dataset from the Canadian Multi-Regional CP Registry (CCPR) and instrumental variables related to the mother's location of residence around birth.

Results: We find that differences in hospitals' intensities are not associated with differences in clinically relevant, long-term CP health outcomes.

Conclusions: Our results suggest that existing matching mechanism of births to hospitals within large metropolitan areas could be improved by early detection of high risk births and subsequent referral of these births to high intensity birthing centers. Substantial hospitalization costs might be averted to Canadian healthcare system ( $\$ 16$ million with a $95 \% \mathrm{Cl}$ of $\$ 6,131,184$ - $\$ 24,103,478$ ) if CP related births were assigned to low intensity hospitals and subsequently transferred if necessary to high intensity hospitals.
\end{abstract}

Keywords: Neonatal care, Hospital intensity, Hospital costs, Long-term outcomes

\section{Introduction}

Hospital costs are a major driver of overall healthcare expenditures, especially in countries with a universal healthcare system where access to expensive health facilities is virtually unrestricted, but essentially geographically circumscribed due to high travel costs. Rising hospitalization costs related to neonatal care is particularly a growing concern for policymakers in developed

\footnotetext{
* Correspondence: cbolboc1@uthsc.edu

'Department of Preventive Medicine, University of Tennessee Health Science Centre, 66 N. Pauline Street, Memphis, TN 38163, USA

${ }^{2}$ The Centre for Addiction and Mental Health, Toronto, Ontario, 33 Russell St, Toronto, ON M5S 2S1, Canada

Full list of author information is available at the end of the article
}

countries [1-3]. Although advances in neonatal care are linked to gains in survival and other meaningful health outcomes, the high costs associated with birthing hospitals requires decision makers to explore methods that optimize neonatal healthcare delivery.

Balancing the fundamental tradeoff between increasing costs of new technological advances and of neonatal care and ability to save lives of the majority, even the sickest and smallest newborns has become a challenge for healthcare systems in North America. Perinatal regionalization-the tiered provision of neonatal care-has emerged over time as a strategy to balance this fundamental tradeoff. This approach provides optimal risk-appropriate maternal child 
services for geographically dispersed populations. These systems of regional tiered perinatal services, now common across North America and around the world, are linked to improved outcomes for high-risk infants born either preterm or with serious medical or surgical conditions [4-6].

Regionalization of perinatal care has facilitated the diffusion of newly-developed neonatal technologies and has improved access of newborns in the community to innovative interventions including therapeutic hypothermia. The impact of improved neonatal interventions in early childhood on later life outcomes is documented and continues to grow in economics literature on the topic. Specifically, Bharadwaj et al. show that children who receive extra medical care at birth have lower mortality rates and later in life achieved higher test scores and better grades in school [7]. Conversely, Figlio et al. argue that the effects of poor neonatal health on adult outcomes are pervasive [8]. Cutler and Meara evaluated the care for low birth weight infants and their results ultimately indicated that medical spending for aggressive care at birth is worthwhile [9]. The extant clinical and health research demonstrates the links between perinatal regionalization with improved neonatal outcomes for infants born preterm and with low birth weight [10].

Although research shows that early health interventions lead to improvements, there is mounting concern regarding the high costs of neonatal intensive care alongside the substantial financial burden survivors of neonatal intensive care might pose on their families and healthcare system $[3,11]$. While the overall efficacy of specific advances in neonatal medicine has been established in the literature [12-14], limited evidence currently exists on the overall effectiveness of technological change in neonatal care; particularly regarding its impact on long-term health outcomes.

This study examines the effect of hospital intensity around birth on the long-term health outcomes by analyzing data drawn from the CCPR. The level of care at birth hospitals directly impacts the type of therapy a newborn receives immediately following their birth. Thus, level of care is critical to treat any potentially adverse events during labor and delivery and it determines the later severity of CP. As such, we evaluated the relationship between hospital type around birth (high intensity, Level III or Level II hospital vs low intensity, or Level I hospital) and CP non-ambulatory status.

The challenge in examining the relationship between hospital type and CP non-ambulatory status is the level of care available around birth is not randomly assigned. Thus, hospital type (high intensity vs low intensity) at birth is our potentially endogenous regressor. We aimed to correct for selection bias which originates as a result of high-risk pregnancies and births more likely taking place in high intensity hospitals (Level III, II). To remove the effects of selection bias on estimates we exploit uneven geographical distribution of high intensity hospitals across Canada, and unique etiology of CP. In particular, we instrument the choice of birth hospital using instrumental variables related to the mother's location of residence around birth (indicators for central metropolitan areas and physical distance from mother's residence at birth to the closest high intensity hospital). The basic intuition here is that within the Canadian universal healthcare system the mother's location of residence around birth provides plausibly exogenous variation in hospital choice. Moreover, proximity determines travel costs and therefore the access to high intensity hospitals for a geographically dispersed population. This enables us to compare births and associated outcomes assigned to hospitals with different treatment intensities.

We focus on children diagnosed with CP for two specific reasons. First, our exclusion restriction comes from the etiology of the condition, particularly the mother's location of residence around birth, as this is orthogonal to all currently known CP biological determinants (we provide empirical evidence for this statement). According to Mosalli [15] the severity of the condition could be lessen if any form of treatment such as access to therapeutic hypothermia were available. However, that this treatment is only available at Canadian high intensity hospitals, and can be clinically effective within the first six hours of life. Moreover, infants are not anymore eligible for cooling if therapeutic hypothermia cannot be initiated after the critical window of the first $6 \mathrm{~h}$ of life. Second, our dataset includes all of the currently known risk factors associated with $\mathrm{CP}$ which in turn allows us to control for essentially all known physiological pathways to exclude an alternative explanation. We further used resampling methods to test the hypothesis that the distribution of clinical, social and economic covariates is consistent with random assignment with respect to the mother's residence at birth (rural vs urban).

We have two primary findings. First, we found robust evidence that birth at high intensity hospitals does not lessen eventual CP severity, despite the fact that only these types of hospitals have clinically effective technology related to the outcome. This finding means that differences in the clinically effective technology across hospitals are not associated at the margin with the severity of the condition. We performed a resampling analysis to test the validity of our instruments and the hypothesis that children in our dataset have the same distribution of covariates across rural and urban areas. Second, we found that the distribution of a group of covariates between urban and rural areas did not differ significantly from 1000 random reassignments of existing patients between rural and urban areas. This suggest that the assignment of CP related births to types of hospitals is 
essentially random. Our results indicate that there is no gain found in increasing the assignment of $\mathrm{CP}$ related births to high intensity hospitals.

Our findings suggest that substantial healthcare costs could be averted within the Canadian healthcare system if CP related births were assigned to low intensity hospitals and subsequently transferred if necessary to high intensity hospitals. We question the conventional wisdom that treatment at high intensity hospitals results, by default, into more effective long-term health outcomes. Our estimates suggest that the Canadian healthcare system could save around $\$ 16$ million per year in hospitalization costs under the scenario where $\mathrm{CP}$ related births were first assigned to less intensive hospitals and subsequently transferred to high intensity hospitals if necessary (for example after an event of intrapartum fetal distress).

The study proceeds as follows. Section 1 provides an outline of relevant medical background, and presents the unique features of the $\mathrm{CP}$ etiologic mechanism. Details regarding our data sources along with sample inclusion and exclusion criteria are provided in Section 2. Section 3 begins by outlining our empirical framework and details the estimation strategy. In this section we also report our main estimates and explore the robustness of these results. We present the results of cost-benefit analysis in section 4, offer discussions in Section 5 and conclude in Section 6.

\section{Background}

\section{Cerebral palsy}

$\mathrm{CP}$ is a set of variable heterogeneous clinical symptoms which result from either an anomaly and/or acquired injuries to the motor regions of the brain [16], causing graded levels of observable neuro-motor dysfunction [17]. CP remains the largest single cause of childhood physical disability in the developed world [18] and it is estimated to affect approximately 2.5-4.0 infants per 1000 live births [19-23].

Although onset occurs at birth or in early childhood, $\mathrm{CP}$ persists throughout an individual's life leaving patients to incur a significant economic burden. In 2003, the U.S. Center for Disease Control (CDC) and Prevention estimated the lifetime costs of $\mathrm{CP}$ per individual to be $\$ 921,000$ USD [24]. A more recent Danish study from 2009 , reports the approximate lifetime cost of CP was $€ 860,000$ for men and $€ 800,000$ for women. The largest component of these expenditures was social care costs, particularly during childhood [25]; however, the lifetime costs of CP depends on the condition's severity and associated comorbid conditions (e.g. intellectual disability, epilepsy, etc.).

$\mathrm{CP}$ is often linked to intrapartum events specifically intrapartum hypoxia [26]. Allegations of obstetrical clinical negligence are commonly cited as a cause of CP and usually focus on the obstetrical care provided in the intrapartum period $[27,28]$. We are aware of only one study which explored the relationship between the quality of care given to a mother during labor and delivery and later CP. An association between suboptimal care and $\mathrm{CP}$ was found in a small proportion of $\mathrm{CP}$ cases [29]. However, previous research did not control for the level of immediate neonatal and postnatal care available following labor and delivery. The relationship between the level of neonatal care available at birth, perinatal and neonatal factors, and the severity of $\mathrm{CP}$ is not yet presently known.

\section{Cerebral palsy and intrapartum events - a narrow window of opportunity}

Acquired brain injuries during labor and delivery, such as perinatal asphyxia, can cause cerebral palsy. Perinatal asphyxia affects 3-5 infants per 1000 live births, with 0.5-1 infants per 1000 live births developing brain damage in the form of neonatal encephalopathy (NE) [30]. Evidence of at least two of the following indicates presence of intrapartum hypoxia: Apgar score of 5 or less at $10 \mathrm{~min}$; need for mechanical ventilation; metabolic or mixed acidosis, or any infant blood gas within the first hour of life showing a $\mathrm{pH}$ of 7 or less or a base deficit of $\geq 16 \mathrm{mmol} / \mathrm{l}[15]$.

The level of care at the birth hospital plays a crucial role in reducing the disability after an acquired brain injury. Consistent standards of level of neonatal care across Quebec, Canada, indicate that the standard of care is available for NE such as: mechanical ventilation and access to therapeutic hypothermia is available at hospitals with NICUs $[15,31]$. In a typical childbirth the baby born in a nursery who suffers from fetal distress is resuscitated and transferred for additional care to Level III hospital. The benefit of neonatal intensive care, however, may only be clinically effective within a narrow window of opportunity and during the first hours of life. For example, infants are no longer eligible for cooling if therapeutic hypothermia cannot be initiated within the first $6 \mathrm{~h}$ of life [15].

\section{Perinatal regionalization}

The concept of perinatal regionalization emerged in North America, first in Canada [32], followed in the U.S. in 1971 by the American Medical Association's House of Delegates' report [33]. Birth hospitals were classified into one of three levels based on the degree of complexity of maternal and perinatal care each was capable of providing. European countries implemented a decentralized maternity services in order to ensure good access to necessary care independent of a mother's place of residence [34]. Moreover, recent research have shown that 
type of hospital is not the main determinant of hospital financial performance in Europe [35].

There is a large body of clinical literature that demonstrates how high-risk infants have better health outcomes in delivery hospitals with neonatal care. In a comprehensive review of 41 published studies conducted between 1979 and 2008, involving the use of different research designs Lasswell et al. [10] concluded: "for very low-birth-weight and very preterm infants, birth outside of a Level III hospital is significantly associated with an increased likelihood of neonatal or predischarge death.".

Due to its size and relatively sparse population, Canada has a highly regionalized neonatal-perinatal care system and nearly all births take place in public hospitals. Nurseries (birthing centers and Level I care) are designed to accommodate the high-number of low-risk births, while specialty care (Level II) and subspecialty care (Level III) accommodate the needs of medium and high-risk births. This classification denotes the differences in the level of perinatal resources and obstetric competence available at a specific birth hospital.

\section{Provider incentives}

Healthcare providers in Canada do not have the financial incentives to refer patients to high or low intensity hospitals. Moreover, there are no clinical guidelines in Canada for a referral to a high vs low intensity birth hospital. This implies that geographic accessibility is the primary determinant of choice of maternity care providers in Canada [36] like in European countries with a universal healthcare system [37]. We thus use mother's residence at birth to instrument for level of care at the birth hospital.

\section{Material and methods \\ Data}

The study was conducted using Quebec provincial data from the CCPR as the level of neonatal care at birthing center was available only for this province. Children with CP born in 1999 or later were enrolled within six of the province's 17 administrative health regions, capturing approximately half of the province's population within the CCPR. Parental consent is obtained and maternal medical and obstetric records, as well as the child's neonatal, medical, and rehabilitation records, are reviewed. These data are supplemented by a standardized parental interview and physical examination of the child by a pediatric neurologist, developmental pediatrician, or child physiatrist. For each enrolled child, more than 120 variables are collected and entered into a Research Electronic Database Capture database. To be enrolled in CCPR, a child must be at least 2 years of age and meet diagnostic criteria for $\mathrm{CP}$, including a clinical diagnosis of a non-progressive motor impairment resulting from a presumably early injury to the developing brain [17].

Children within the CCPR included for analysis in this study were born between 1999 and 2014 in the province of Quebec. Children with CP diagnosis linked to any identified post-neonatal cause or cases born outside the province of Quebec were excluded from our investigation.

For our analysis, we classified children according to the level of neonatal care available at birth hospital [38]. In Quebec maternity care is regionalized and nearly all deliveries take place in public hospitals or birthing centers. ${ }^{1}$ This classification reflects differences in the level of perinatal resources and obstetric competence available at a specific birth hospital. We used clear, uniform definitions and consistent standards to classify the level of neonatal care across the study sites, and made appropriate adjustments for differences in case mix between the three groups of hospitals. We classified each hospital delivery unit according to its level of neonatal care using the policy statement on this topic provided by the American Academy of Pediatrics [38] (Appendix). This classification reflects differences in the level of obstetric and neonatal competences available at the birth hospital, and is outlined in further detail in Appendix.

In brief, nurseries are designed to provide care for newborns 34 weeks gestation or more, and can offer intravenous therapy, phototherapy and gavage feeding; Level II centers provide care for newborns 30 weeks gestation or more, and in addition to level I services can offer non-invasive ventilation or endotracheal intubation. Level III centers care for newborns regardless of gestational age and in addition to the above services offer nitric oxide therapy, therapeutic hypothermia along with immediate access to a complete range of pediatric subspecialties, imaging, and surgeries.

The outcome used for this analysis was CP nonambulatory status, as defined by a Gross Motor Function Classification System (GMFCS) level IV or level V [40]. The major challenge for our research was to control for case-mix differences between types of hospitals. In particular, Level II and Level III hospitals have a higher proportion of medium and high-risk pregnancies compared with Level I hospitals for obvious reasons. We used a quasi-experimental study design [41], controlling for relevant covariates in order to control for selection bias that could originate from the differences in case mix between the three groups of hospitals. Our rich dataset allowed us to control for all known risk factors related to etiology of $\mathrm{CP}$.

\footnotetext{
${ }^{1}$ Hospitals in Quebec are not-profit entities. As non-for profit organizations, public hospitals organizations are expected to be efficiently use limited healthcare resources [39].
} 
We used current clinical practice guidelines in obstetrics and gynecology [42], perinatal surveillance literature [43], CP risk factors [44] and clinical judgment to choose explanatory variables and to make proper adjustments for differences in case-mix between different delivery hospitals. The following covariates were used to control for possible selection bias: birth weight, gestational age, preeclampsia, gestational diabetes, bleeding during pregnancy, severe illness during pregnancy, accident or trauma during pregnancy, preterm birth, a family history of $\mathrm{CP}$, low maternal education (lacking a high school diploma), maternal age, and history of drug use. We also controlled for perinatal asphyxia, which was defined as neonatal encephalopathy with at least three of the following criteria: an Apgar score $<5$ at $10 \mathrm{~min}$, a cord $\mathrm{pH}$ of $<7.0$, a cord base excess $>16$, an abnormal fetal heart rate such as tachycardia ( $>160$ beats per minute) or bradycardia ( $<120$ beats per minute), presence of meconium, need for intubation, delay in spontaneous respiration, need for resuscitation of the newborn, or abnormal imaging results consistent with hypoxic ischemic injury.
Our cohort of 825 children with CP without any postneonatal cause were born in Quebec between 1999 and 2014. Forty-seven percent were born in birth sites with Level III neonatal care, $21 \%$ with Level II and the remainder (31\%) with Level I neonatal care. Nonambulatory status (Gross Motor Function Classification System level IV and level V) was reported in $27 \%$ of the cases. The other characteristics of the sample are presented in Table 1.

\section{Empirical strategy \\ Overview}

Our empirical objective was to isolate the causal effect of hospital intensity (high intensity - level III or level II vs low intensity level I) available at birth on the probability of being diagnosed with the least severe Cerebral Palsy type. The challenge in examining this research question is that the level of neonatal care at birth is not randomly assigned. We therefore offer an identification strategy that does not rely on random assignment. We employ resampling techniques to test the hypothesis that covariate distributions across the mother's residence at

Table 1 General Characteristics of the Population

\begin{tabular}{|c|c|}
\hline Variables & Children with $C P(N=825)$ \\
\hline \multicolumn{2}{|l|}{ Level of Service at Delivery } \\
\hline Level I (\%) & 31 \\
\hline Level II (\%) & 21.6 \\
\hline Level III (\%) & 47.4 \\
\hline Non-Ambulatory Status (GMFCS IV-V) (\%) & 26.7 \\
\hline Maternal Age, mean $\pm S D$ & $29.64 \pm 5.6$ \\
\hline \multicolumn{2}{|l|}{ Mother's ethnic group } \\
\hline Caucasian (\%) & 78.76 \\
\hline \multicolumn{2}{|l|}{ Education } \\
\hline High school or more education (\%) & 78.06 \\
\hline Less than high school education (\%) & 21.94 \\
\hline Family History of CP (\%) & 4.14 \\
\hline Resuscitation at birth (\%) & 38.25 \\
\hline \multicolumn{2}{|l|}{ Type of Pregnancy } \\
\hline Single foetus (\%) & 89.2 \\
\hline Pre-eclampsia (\%) & 7.7 \\
\hline Gestational Diabetes (\%) & 11.4 \\
\hline Bleeding during first trimester of pregnancy (\%) & 18.9 \\
\hline Severe Illness during Pregnancy (\%) & 28 \\
\hline Accident or Trauma during Pregnancy (\%) & 13 \\
\hline Birth weight (gram), mean $\pm S D$ & $2645 \pm 1007.1,663$ \\
\hline Gestational age (weeks), mean $\pm S D$ & $35.73 \pm 4.9663$ \\
\hline Prematurity (<37 weeks) (\%) & 46.8 \\
\hline Perinatal Asphyxia (\%) & 12.04 \\
\hline
\end{tabular}


time of birth (rural and urban areas) are consistent with random assignment.

\section{Implementation}

Instrumental variables and generalized method of moments We used multivariate instrumental variables regression along with generalized method of moments, which allows for unobserved risk factors that affect the choice of hospital type and outcomes conditional on that choice, but which often suffers from imprecise estimates. Instrumental variables estimation uses additional covariates that influence the choice of birth hospital but which do not influence CP severity.

Geographic accessibility is one of the most significant determinants of the type of maternity care providers in Canada [36] as in European countries with a universal healthcare system [37]. We thus use mother's residence at birth to instrument for level of care at birth hospital. In particular, pregnant women residing within census metropolitan areas are more likely to give birth in hospitals with level II, or level III neonatal care as these types of hospitals are located in large metropolitan areas. However, the type of residence is orthogonal to unobserved components of CP non-ambulatory status as given that the type of residence (rural vs, urban) is not systematically related to clinical pathways and etiology of this neurological disease. Because of this, the mothers' residence at birth should in theory be a good statistical instrument. We further used resampling methods to test the hypothesis that the distribution of clinical, social and economic covariates is consistent with random assignment with respect to mothers ' residence at birth (rural vs. urban). ${ }^{2}$

In the first stage of estimation, we predicted the type of hospital at birth using exogenous indicators for greater Montreal, Quebec City, Gatineau, Sherbrooke, or an indicator for a census metropolitan area. We used Statistics Canada classification of census metropolitan areas to construct a central metropolitan area indicator as well as Population and Dwellings Counts for Canada.

$$
D_{i}=\pi_{0}+\pi_{1} Z_{i}+X_{i}^{\prime} \pi+\varepsilon_{i}
$$

Our primary equation of interest was the second stage, in which we regress CP non-ambulatory status on the predicted probability of hospital type $\widehat{D}_{i}$ and other covariates:

\footnotetext{
${ }^{2}$ To instrument for hospital intensity we also used physical distance between mother's residence at birth and closest high intensity hospital. We used Google's Distance Matrix API. Our results did not change.
}

$$
Y_{i}=\beta_{0}+\beta_{1} \widehat{D}_{i}+X_{i}^{\prime} \gamma+e_{i}
$$

In order for our estimation approach to deliver consistent parameter estimates, the instruments $Z_{i}$ from our first stage must not directly affect CP non-ambulatory status and be uncorrelated with the unexplained variation of CP non-ambulatory status. The evidence presented in Table 4 indicates our instruments are very strong and relevant.

Maternal residence at birth may not always be a perfect predictor for the level of neonatal care at delivery hospitals, especially in large metropolitan areas. In Montreal for example, a pregnant woman can choose either level of NICU. However, we believe that mothers' residence at birth is the strongest determinant of the birthing hospital given the peculiarities of a universal healthcare system in Canada. Thus, ceteris paribus, a pregnant woman is more likely to choose a delivery hospital with the highest available NICU in the area, which is Level III, or Level II in metropolitan areas.

\section{Endogenous bivariate Probit model}

We also estimated this model using a bi-variate probit regression, where both the type of hospital at birth, $D_{i}$, and CP non-ambulatory status, $Y_{i}$, are estimated as functions of the standard normal probability distribution function, $\mathrm{P}[$.$] . The first stage can be written:$

$D_{i}=P\left[\pi_{0}+\pi_{1} Z_{i}+X_{i}^{\prime} \pi+\varepsilon_{j}\right]$,

and the outcome is determined by:

$$
Y_{i}=P\left[\beta_{0}+\beta_{1} D_{i}+X_{i}^{\prime} \gamma+e_{i}\right] .
$$

The correlation between $e_{i}$, $\varepsilon_{i}$ is the source of omitted variable bias. The identification requires that excluded instruments $Z_{i}$ be independent of $e_{i}, \varepsilon_{i}$, which are assumed to be normally distributed. Given the distributional assumptions imposed on error terms this model can be estimated using maximum likelihood estimation.

\section{Resampling}

For our results to be a credible estimate of the effect of hospital type on CP non-ambulatory status, it was necessary to rule out the possibility that children born with $C P$ in rural areas differ systematically from children born with CP in urban areas, lest differences in CP nonambulatory status be caused by these differences instead of differences in birth hospital type. To test for this, we compared the distributions of urban versus rural statistical characteristics to distributions derived of these same summary statistics where existing children were randomly assigned to urban and rural residences. If the statistical characteristics of urban and rural CP cases are statistically indistinguishable, the proportion of MannWhitney difference of means tests using randomly 
Table 2 Resampling

\begin{tabular}{lllll}
\hline & Specification 1 & Specification 2 & Specification 3 & Specification 4 \\
\hline Empirical p-values (means and standard deviation) & $0.491(0.272)$ & $0.498(0.230)$ & $0.510(0.246)$ & $0.52(0.245)$ \\
Kolmogorov-Smirnov test p-value & 0.641 & 0.273 & 0.401 & 0.179
\end{tabular}

Specification 1 (17 variables) includes the following variables: number of pregnancies, number of births known, number of still births, number of abortions, number of miscarriages, number of premature children known, fertility treatments used, dummy if the child had presented with convulsions, sex of the child, dummy for in vitro fertilization

Specification 2 (38 variables) includes additionally the following variables: preeclampsia, eclampsia, presence of chorioamnionitis, resuscitation at birth indicator, bleeding during the first trimester, bleeding during the second semester, bleeding during the third trimester, alcohol during pregnancy, tobacco during pregnancy, hypertension gestational diabetes, trauma during pregnancy, drugs during pregnancy, number of premature children known, $\mathrm{CP}$ family history, gestational hypertension, intrapartum asphyxia, neonatal encephalopathy, cooling, encephalopathy

Specification 3 (50 variables) includes additionally the following variables: non-ambulatory CP status, presence of post-neonatal cause, type of delivery, number of gestation weeks, head circumference, birthweight, number of hospitalization days during pregnancy, Apgar score at 1 min, Apgar score at 5 min, Apgar score at $10 \mathrm{~min}$, last recorded head circumference, age at the initial registration

Specification 4 (56 variables) includes additionally the following variables: mother's age at time of birth, dummy for single pregnancy, prescription drugs indicator, severe illness during pregnancy, gross motor function classification of CP severity, severity of encephalopathy, non-ambulatory CP status, presence of post-neonatal cause, type of delivery, number of gestation weeks, head circumference, birthweight, number of hospitalization days during pregnancy, Apgar score at $1 \mathrm{~min}$, Apgar score at $5 \mathrm{~min}$, Apgar score at $10 \mathrm{~min}$, last recorded head circumference, age at the initial registration

assigned residences that are less than the Mann-Whitney test for actual urban vs. rural residences (empirical pvalue) will be uniformly distributed from 0 to 1 . A test of whether a group of empirical p-values representing multiple statistical attributes of CP cases is uniformly distributed is an effective test of whether the statistical attributes of urban versus rural CP cases differ systematically. (Good, 2006; Carrell and West, 2009).

\section{Results}

Table 2 contains the results of our resampling analysis. In the first column, we tested the differences in urban versus rural means of the 17 health covariates listed in the notes to Table 2 . We failed to reject the null hypothesis of a uniform distribution of the empirical p-vales, which is consistent with these 17 variables having the same means jointly for urban versus rural $\mathrm{CP}$ cases. In subsequent columns, we add additional covariates, concluding with 52 covariates in Column 4 . In each case, we failed to reject the null of no difference in all covariate means jointly for urban versus rural $\mathrm{CP}$ cases. We present results from a linear probability model estimated by Ordinary Least Squares (OLS) in Table 3. This simplest possible estimation technique would not provide consistent estimates of the causal effect of the level of care on the ambulatory status of children with $\mathrm{CP}$ if indeed the level of care is not randomly assigned. ${ }^{3}$ With this caveat, we did not find evidence that the level of care affects the $\mathrm{CP}$ ambulatory status using OLS. The coefficient on the first line of Table $3,-0.0349$, is not significantly different from zero.

In Tables 4, 5 and 6, we estimated the effects of level of care using the instrument of the mother's residence at

\footnotetext{
${ }^{3}$ Since the level of care can be influenced by self-selection, it would by definition be non-random and require estimation using exogenous instruments. However, statistical tests reported in Table 4 fail to find evidence of non-random assignment.
}

birth to correct for endogeneity of treatment level. Using three different estimation techniques (2-Step GMM, Endogenous Bivariate Probit, and 2SLS), we were again unable to find significant evidence that the level of care available at time of birth impacts the later $\mathrm{CP}$ nonambulatory status.

In the first column of Table 4, we included a number of test statistics assessing the quality of our models. We report $p$-values from the Hansen J test for overidentifying restrictions, the Anderson-Rubin Wald test of joint significance of the program effects that is robust to weak identification, as well as the Angrist-Pischke multivariate F-test of excluded instruments. We found that our

Table 3 Linear Probability Model Results ${ }^{\mathrm{a}}$

\begin{tabular}{ll}
\hline VARIABLES & Linear regression \\
\hline Level III or II vs Level I & $-0.0349[0.047]$ \\
Asphyxia & $0.2647^{* *}[0.071]$ \\
Preeclampsia & $0.1597+[0.095]$ \\
Blood during the first trimester & $0.0912+[0.049]$ \\
Severe illness during pregnancy & $-0.0152[0.050]$ \\
Preterm birth & $0.1860^{*}[0.079]$ \\
Birthweight & $0.0001[0.000]$ \\
Years of maternal education & $-0.0001[0.012]$ \\
Mother's age at time of birth & $0.0040[0.004]$ \\
Vaginal delivery & $0.0514[0.124]$ \\
Vaginal delivery after cesarean & $-0.1369^{* *}[0.043]$ \\
Drugs & $0.1495[0.136]$ \\
Hypertension & $0.1630^{*}[0.074]$ \\
Trauma & $-0.0081[0.059]$ \\
Family CP history & $-0.1053[0.088]$ \\
Observations & 825 \\
R-squared & 0.08 \\
\hline
\end{tabular}

*** $p<0.01, * * p<0.05, * 0<0.1$

a Level I hospitals are the base category. Robust standard errors in brackets 
Table 4 Instrumental Variables Results (Level III\& vs Level I)

\begin{tabular}{|c|c|c|}
\hline LEVELS & 2-Step GMM & Endogenous bivariate probit \\
\hline III\& vs I & $0.006[0.128]$ & $0.01[0.03]$ \\
\hline Observations & 825 & 825 \\
\hline Overid & 0.281 & \\
\hline Overid P-val & 0.87 & \\
\hline F-test & 47.9 & \\
\hline Endog & 0.02 & \\
\hline Endog P-val & 0.87 & \\
\hline Rho & & $-0.08[0.258]$ \\
\hline Chi-sq & & 0.001 \\
\hline F-analog & & 65,341 \\
\hline Exon P-val & & 0.914 \\
\hline \multicolumn{3}{|c|}{$\begin{array}{l}\text { F** }^{* *} p<0.01, * * p<0.05 \\
\text { a Table presents reduced form estimates of the effects of interest from two } \\
\text { stage least squares, generalized method of moments, endogenous bivariate } \\
\text { probit. Robust standard errors in brackets. }{ }^{* *} p<0.01,{ }^{* *} p<0.05 \text {. Over is the } \\
\text { Hansen J test for overidentification; Endog is a test for endogeneity of } \\
\text { exposure variable; F-test is Angrist-Pischke multivariate F-test of excluded } \\
\text { instruments; Chi-sq is Wald test of Rho }=0 \text {. F-analog is the test of joint } \\
\text { significance of instrumental variables. Exon P-val is the smallest } p \text {-value of the } \\
\text { excluded instrument in the regression of residuals on covariates and } \\
\text { instrumental variables. } 2 \mathrm{SLS} \text { estimates are numerically equivalent } 2 \text {-Step GMM } \\
\text { up to two decimal places }\end{array}$} \\
\hline
\end{tabular}

up to two decimal places
Table 6 Second stage complete results (Level II \& III vs Level I) ${ }^{\text {a }}$

\begin{tabular}{|c|c|}
\hline VARIABLES & \\
\hline \multirow[t]{2}{*}{ Level III or II vs Level I } & -0.0565 \\
\hline & {$[0.129]$} \\
\hline \multirow[t]{2}{*}{ Intrapartum Asphyxia } & $0.2676^{* *}$ \\
\hline & {$[0.070]$} \\
\hline \multirow[t]{2}{*}{ Preeclampsia } & $0.1594+$ \\
\hline & {$[0.093]$} \\
\hline \multirow[t]{2}{*}{ Blood during the first trimester } & $0.0935+$ \\
\hline & {$[0.049]$} \\
\hline \multirow[t]{2}{*}{ Severe illness during pregnancy } & -0.0145 \\
\hline & {$[0.049]$} \\
\hline \multirow[t]{2}{*}{ Preterm birth } & $0.1884^{*}$ \\
\hline & {$[0.077]$} \\
\hline \multirow[t]{2}{*}{ Birthweight } & 0.0000 \\
\hline & {$[0.000]$} \\
\hline \multirow[t]{2}{*}{ Years of maternal education } & 0.0014 \\
\hline & {$[0.012]$} \\
\hline \multirow[t]{2}{*}{ Mother's age at time of birth } & 0.0039 \\
\hline & {$[0.004]$} \\
\hline \multirow[t]{2}{*}{ Vaginal delivery } & 0.0507 \\
\hline & {$[0.121]$} \\
\hline \multirow[t]{2}{*}{ Vaginal delivery after cesarean } & $-0.1342^{* *}$ \\
\hline & {$[0.042]$} \\
\hline \multirow[t]{2}{*}{ Drugs } & 0.1469 \\
\hline & {$[0.135]$} \\
\hline \multirow[t]{2}{*}{ Hypertension } & $0.1629^{*}$ \\
\hline & {$[0.072]$} \\
\hline \multirow[t]{2}{*}{ Trauma } & $-0.008^{*}$ \\
\hline & {$[0.057]$} \\
\hline \multirow[t]{2}{*}{ Family CP history } & -0.102 \\
\hline & {$[0.08]$} \\
\hline Observations & 825 \\
\hline
\end{tabular}

${ }^{a}$ Robust standard errors in brackets. Centered R-squared $=0.31$

instruments were not weak (F-statistic of $47.9>10$ ), and that the model is not overidentified. However, the test of endogeneity did not reject the null hypothesis that treatment variable can be treated as an exogenous regressor.

We present the estimated causal effect of level of care on ambulatory status using an endogenous bivariate probit model in Column 2 of Table 4. The standard error of the estimated effect [0.03] is dramatically lower than for the other 2 instrumental variables techniques, indicating a more precise estimation of any effect. Here again, we did not find any significant effect of the level of care on ambulatory status. Tables 5 and 6 present the first and second stages of 2-Stage Least Squares (2SLS) estimates

** $p<0.01, * p<0.05,+p<0.1$

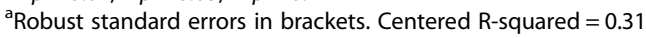


of treatment effects. The coefficient of interest, as seen on the first line of Table 6, again did not significantly differ from zero.

\section{Cost-benefit analysis}

Neonatal care in Canada and around the world is extremely expensive. Healthcare systems aim to find optimal ways to deliver increasingly expensive neonatal care. For example, Gavurova et al. show that in Slovakia day surgeries related to Gynaecology and Obstetrics had increased significantly after this form of healthcare provision was regulated in 2004 [45]. In Canada the cost of treatment in an ICU and the cost per general ward varies by the type of facility. For example, in British Columbia according to 2014/2015 Interprovincial reciprocal billing rates, the cost of an ICU per day varies from $\$ 1949$ to $\$ 5317$ and the cost for a general ward per day varies from $\$ 803$ to $\$ 2794$ per day 1 [46]. We estimate the savings related to hospitalization costs only from a hypothetical alternative assignment of births at risk of $\mathrm{CP}$ to maternity facilities rather than the higher level of care facilities currently observed in the data.

For our cost-benefit analysis we used a 3.8 per 1000 live births incidence rate of $\mathrm{CP}$ and a projected number of 391,414 births for 2016 in Canada. It is expected that 1523 children with CP will be born in Canada in 2016. For our computations we also used the lowest rates from the literature of $\$ 1628.60$ per ICU day and $\$ 388$ per ward [47].

Our data contains the number of hospital days for each patient, stratified into general ward and intensive care unit. The median hospitalization days for CP children born in a level I hospital is 6 days. The median number of hospitalization days for $\mathrm{CP}$ children born in level II, or level III care is 28.5 days, and the difference in hospitalization days between two types of hospitals is 23 days (95\% CI, 17.06-28.94) per patient. A little over $20 \%$ of CP children born in level I hospital are subsequently transferred to level II or level III hospitals.

Under these assumptions the total cost related to hospitalization days given current matching of CP births to maternity facilities is $\$ 49,875,355$. However, if CP related births were assigned to nurseries and transferred subsequently to hospitals with NICU, the overall total hospitalization costs would decline to a little over \$34 million per year, saving the Canadian healthcare system around \$15,865,600 (95\% CI: \$6,131,184 - \$24,103,478). Our estimates suggest that significant hospitalization costs might be averted if pregnant women at risk of having a CP child would give birth in level I care and then be transported to a level II, or Level III after birth if necessary. One limitation of our cost-benefit analysis is that mothers at risk of having a CP child are not identified in advance. However, this is a lower bound of savings given that many direct healthcare costs were excluded from analysis.

\section{Discussion}

We have shown that differences in the level of neonatal care, and associated medical technology available at the time of birth, do not significantly affect the risk of $\mathrm{CP}$ non-ambulatory status. This finding is consistent and robust across methods based on selection on observable assumption as well as using methods based on selection on unobservables documented in this paper. Instrumental variables estimation allowed us to control for possible unobserved selection effects and we were not able to find a significant relationship between the level of neonatal care at birth hospital and CP non-ambulatory status across all estimated models. Resampling analysis revealed that the distribution of clinical, social and economic covariates appears to be consistent with random reassignment with respect to location at birth (rural vs urban). Our cost-benefit analysis suggests that around $\$ 16$ million per year in healthcare savings could accrue to the Canadian Healthcare system if CP related births were assigned to nurseries and subsequently transferred to level II, or III hospitals if necessary.

The lack of incremental impact of the level of neonatal care at the time of birth on the later risk of CP nonambulatory status likely demonstrates the benefit of the development and generalization of the neonatal resuscitation program (NRP). The NRP educational program for North American healthcare providers working in the delivery rooms and nurseries is designed to aid in learning the cognitive and technical skills required for effective evidence-based resuscitation of newborn babies and appropriate referral to specialized centers as soon as possible $[48,49]$. Neonatal resuscitation was shown to reduce mortality from intrapartum related events $[26,50,51]$, such as perinatal asphyxia, and might explain the lack of effect found in our study.

Our study has several limitations. The methods employed cannot replace a prospective randomized controlled trial (RCT), and may not have fully controlled for selection effects or unobserved covariates. However, a RCT that would assess the impact of levels of neonatal care available at hospitals where delivery was carried out on CP ambulatory status is unlikely to be implemented given pragmatic considerations and concerns. Our study does not discuss the differences in other measures that might be important as well for determination of CP related outcomes of regionalized perinatal care such as fine motor skills, cognition, language, or behavior.

We used maternal residence at birth as an instrument to predict the type of hospital at birth. This may not always be a perfect predictor for the level of neonatal care at delivery hospital especially in large metropolitan areas such as Montreal for example, where the pregnant women can choose either level of NICU. However, geographic accessibility is one of the most significant determinants of 
choice of maternity care providers [36, 37]. Given the peculiarities of a universal healthcare system ceteris paribus, a pregnant woman is more likely to choose a delivery hospital with the highest available level of care.

\section{Conclusion}

Our study provides empirical evidence that the level of care available at birth does not significantly affect the distribution of $\mathrm{CP}$ non-ambulatory cases. The success of the neonatal resuscitation program may contribute to this lack of relationship. This does not mean that neonatal care is not effective, as the overall impact of neonatal interventions on health outcomes is well documented in the health services and economics literature [7-9, 52]. However, our results indicate the potential for significant healthcare related savings within the existing referral process to birthing centers and overall neonatal care rationing.

An equitable and affordable healthcare system requires a constant search for the optimal delivery of increasingly expensive neonatal care. In this study, we have identified that the existing matching mechanism of births to hospitals within large Canadian metropolitan areas could be improved. This means that policy makers could design better triage policies and increase the productivity of limited neonatal healthcare resources'.

\section{Appendix}

\section{Definitions of the levels of the neonatal care used in Quebec}

1A: basic care + phototherapy

1B: greater or equal to 34 weeks of gestation, intravenous therapy, gavage feeding

2A: greater or equal to 32 weeks of gestation, intravenous therapy, gavage feeding

2B: greater or equal to 32 weeks of gestation, intravenous therapy, gavage feeding and ventilation via nasal passage

$2 \mathrm{~B}+$ : greater or equal to 30 weeks of gestation, intravenous therapy, gavage feeding and ventilation via nasal passage or endotracheal ventilation

3A-: greater or equal to 29 weeks of gestation, endotracheal ventilation + NO. Immediate access to all specialists.

3A: care provided to all babies regardless of their gestational age or birth weight. Endotracheal ventilation + NO. Immediate access to all specialists.

3B: level 3A care and complete access to specialists. Imaging tests carried out and interpretation of results done. Surgeries done except for severe cardiac malformations requiring extracorporeal circulation.

3C: Level 3B care + surgical repair of severe cardiac malformations requiring extracorporeal circulation.

\section{Abbreviations}

CP: Cerebral Palsy; NICU: Neonatal Intensive Care Unit; CCPR: Canadian MultiRegional Cerebral Palsy Registry; CDC: The US Center for Disease Control; NE: Neonatal Encephalopathy; GMFCS: Gross Motor Function Classification System; 2SLS: 2-Stage Least Squares; NRP: Neonatal Resuscitation Program; RCT: Randomized Controlled Trial

Acknowledgements

Not applicable

\section{Authors' contributions}

CB conceptualized the study, analyzed and interpreted the data. MS gave medical and was a major contributor in writing the manuscript. All authors read and approved the final manuscript.

\section{Authors' information}

Not applicable.

Funding

Not applicable.

Availability of data and materials

The datasets generated and/or analyzed during the current study are available in the Cerebral Palsy Registry https://www.cpregistry.ca/

Ethics approval and consent to participate

Not applicable.

Consent for publication

Not applicable.

Competing interests

The authors declare that they have no competing interests.

\section{Author details}

${ }^{1}$ Department of Preventive Medicine, University of Tennessee Health Science Centre, 66 N. Pauline Street, Memphis, TN 38163, USA. ${ }^{2}$ The Centre for Addiction and Mental Health, Toronto, Ontario, 33 Russell St, Toronto, ON M5S 2S1, Canada. ${ }^{3}$ Department of Pediatrics, Faculty of Medicine, McGill University, 3605 Rue de la Montagne, Montréal, QC H3G 2M1, Canada.

Received: 15 March 2020 Accepted: 25 June 2020

Published online: 08 July 2020

\section{References}

1. Doyle JJ Jr, Graves JA, Gruber J. Uncovering waste in US healthcare: evidence from ambulance referral patterns. J Health Econ. 2017:54:25-39.

2. Einav, L., Finkelstein, A., \& Mahoney, N. Long-term care hospitals: A case study in waste (no. w24946). National Bureau of Economic Research 2018.

3. Kilpatrick, S.J. et al.. Outcome of infants born at 24-26 weeks' gestation: I. survival and cost. Obstetrics Gynecol 1997; 90(5): 803-8. Available at: http:// www.ncbi.nlm.nih.gov/pubmed/9351768 [Accessed May 16, 2014].

4. Bode, M.M. et al.. Perinatal regionalization and neonatal mortality in North Carolina, 1968-1994. Am J Obstetrics Gynecol 2001 184(6): 1302-7. Available at: http://www.ncbi.nlm.nih.gov/pubmed/11349206 [Accessed May 16, 2014].

5. Clement, M.S. Perinatal care in Arizona 1950-2002: a study of the positive impact of technology, regionalization and the Arizona perinatal trust. J Perinatol 2005; 25(8): 503-8. Available at: http://www.ncbi.nlm.nih.gov/ pubmed/15889131 [Accessed May 16, 2014].

6. Stark, A.R. Levels of neonatal care. Pediatrics 2004 114(5): 1341-7. Available at: http://www.ncbi.nlm.nih.gov/pubmed/15520119 [Accessed May 16, 2014].

7. Bharadwaj, P., Løken, K.V. \& Neilson, C. Early life health interventions and academic achievement. Am Econ Rev 2013 103(5): 1862-1891. Available at: http://www.aeaweb.org/articles.php?doi=10.1257/aer.103.5.1862 [Accessed July 30, 2014]

8. Figlio, D.N. et al. The Effects of Poor Neonatal Health on Children's Cognitive Development 2013. Available at: http://www.nber.org/papers/w1 8846 [Accessed September 24, 2014].

9. Cutler, D.M. \& Meara, E. The Technology of Birth: Is it Worth it? 1999 Available at: http://www.nber.org/papers/w7390 [Accessed April 21, 2016]. 
10. Lasswell, S.M. et al. Perinatal regionalization for very low-birth-weight and very preterm infants: a meta-analysis. JAMA 2010a; 304(9): 992-1000. Available at: http://www.ncbi.nlm.nih.gov/pubmed/20810377 [Accessed May 15, 2014].

11. Bohin, S., Draper, E.S. \& Field, D.J. Impact of extremely immature infants on neonatal services. Archives of disease in childhood. Fetal Neonatal edition 1996 74(2), pp. F110-F113. Available at: http://www.pubmedcentral.nih.gov/ articlerender.fcgi?artid=2528542\&tool=pmcentrez\&rendertype=abstract [Accessed May 16, 2014]

12. Cifuentes, J. et al. Mortality in low birth weight infants according to level of neonatal care at hospital of birth. Pediatrics 2002; 109(5): 745-51. Available at: http://www.ncbi.nlm.nih.gov/pubmed/11986431 [Accessed May 16, 2014].

13. Khurshid, F. et al. Lessons learned during implementation of therapeutic hypothermia for neonatal hypoxic ischemic encephalopathy in a regional transport program in Ontario. Paediatr Child Health,2011; 16(3): 153-156. Available at: http://www.pubmedcentral.nih.gov/articlerender.fcgi?artid= 3077305\&tool=pmcentrez\&rendertype=abstract [Accessed July 14, 2014].

14. Sinclair, J.C. Effectiveness of intensive care of very low birth-weight infants. Mead Johnson Symposium on Perinatal and Developmental Medicine 1982 (20): 23-8. Available at: http://www.ncbi.n/m.nih.gov/pubmed/6242491 [Accessed May 16, 2014].

15. Mosalli, R. Whole body cooling for infants with hypoxic-ischemic encephalopathy. J Clin Neonatol,2012; 1(2): 101-106. Available at: http:// www.pubmedcentral.nih.gov/articlerender.fcgi?artid=3743149\&tool= pmcentrez\&rendertype=abstract [Accessed February 22, 2016].

16. O'Shea, T.M. Diagnosis, treatment, and prevention of cerebral palsy. Clin Obstet Gynecol, 2008; 51(4): 816-828. Available at: http://www. pubmedcentral.nih.gov/articlerender.fcgi?artid=3051278\&tool= pmcentrez\&rendertype=abstract [Accessed July 9, 2014].

17. Rosenbaum, P. et al. A report: the definition and classification of cerebral palsy April 2006. Developmental medicine and child neurology. Supplement 2007 109: 8-14. Available at: http://www.ncbi.nlm.nih.gov/pubmed/173704 77 [Accessed May 26, 2014].

18. Surman, G. et al. Children with cerebral palsy: severity and trends over time. Paediatric Perinatal Epidemiol 2009 23(6): 513-21. Available at: http://www. ncbi.nlm.nih.gov/pubmed/19840287 [Accessed July 9, 2014].

19. Arneson, C.L. et al.. Prevalence of cerebral palsy: autism and developmental disabilities monitoring network, three sites, United States 2004. Disability Health J 2009 2(1); 45-48. Available at: http://www.ncbi.n/m.nih.gov/ pubmed/21122742 [Accessed March 4, 2016].

20. Johnson, A. Prevalence and characteristics of children with cerebral palsy in Europe. Develop Med Child Neurol,2002; 44(09): 633-640. Available at: http:// journals.cambridge.org/abstract_S0012162201002675 [Accessed April 21, 2016].

21. Paneth, N., Hong, T. \& Korzeniewski, S. The descriptive epidemiology of cerebral palsy. Clin Perinatol, 2006 33(2); 251-267. Available at: http://www.perinatology. theclinics.com/article/S009551080600025X/fulltext [Accessed April 2, 2016].

22. Winter, S. et al. Trends in the prevalence of cerebral palsy in a populationbased study. Pediatrics 2002 110(6): 1220-5. Available at: http://www.ncbi. nlm.nih.gov/pubmed/12456922 [Accessed April 21, 2016].

23. Oskoui, M. et al. Prevalence of cerebral palsy in Quebec: alternative approaches. Neuroepidemiol 2013; 40(4): 264-8. Available at: http://www. ncbi.nlm.nih.gov/pubmed/23363886 [Accessed May 17, 2014].

24. CDC. Economic costs associated with mental retardation, cerebral palsy, hearing loss, and vision impairment--United States, 2003. Morbidity Mortality Weekly Report 2004; 53(3): 57-9. Available at: http://www.ncbi.nlm.nih.gov/ pubmed/14749614 [Accessed July 9, 2014].

25. Kruse, M. et al. Lifetime costs of cerebral palsy. Dev Med Child Neurol 2009; 51(8): 622-8. Available at: http://www.ncbi.nlm.nih.gov/pubmed/19416329 [Accessed July 9, 2014].

26. Lee, A.C.C. et al. Neonatal resuscitation and immediate newborn assessment and stimulation for the prevention of neonatal deaths: a systematic review, meta-analysis and Delphi estimation of mortality effect. BMC Public Health 2011;11 Suppl 3: p.S12. Available at: http://www.pubmedcentral.nih.gov/ articlerender.fcgi?artid=3231885\&tool=pmcentrez\&rendertype=abstract [Accessed June 11, 2014].

27. MacLennan, A. et al. Who will deliver our grandchildren? Implications of cerebral palsy litigation. JAMA 2005; 294(13): 1688-90. Available at: http:// www.ncbi.nlm.nih.gov/pubmed/16204669 [Accessed July 9, 2014].

28. Sloan, F.A. et al. No-fault system of compensation for obstetric injury: winners and losers. Obstetrics Gynecol 1998 91(3): 437-43. Available at: http://www.ncbi.nlm.nih.gov/pubmed/9491874 [Accessed July 9, 2014].
29. Gaffney, G. et al. Case-control study of intrapartum care, cerebral palsy, and perinatal death. BMJ, 1994; 308(6931): 743-750. Available at: http://www. bmj.com/content/308/6931/743 [Accessed July 9, 2014].

30. Levene, M.I. et al. Comparison of two methods of predicting outcome in perinatal asphyxia. Lancet,1986; 327(8472): 67-69. Available at: http://www. sciencedirect.com/science/article/pii/S014067368690718X [Accessed April 16, 2016].

31. Vannucci, R.C. Current and potentially new management strategies for perinatal hypoxic-ischemic encephalopathy. Pediatrics 1990 85(6): 961-968. Available at: http://pediatrics.aappublications.org/content/85/6/961.abstract [Accessed April 16, 2016].

32. Department of National Health and Welfare. Recommended standards for maternity and newborn care, Ottawa 1968.

33. AMA House of Delegates. Centralized community or regionalized perinatal intensive care. New Jersey: Atlantic City; 1971.

34. Yu, V.Y.H. \& Dunn, P.M. Development of regionalized perinatal care. Seminars Neonatol 2004 9(2): 89-97. Available at: http://www.ncbi.nlm.nih. gov/pubmed/16256712 [Accessed July 10, 2014].

35. Bem A. et al. Hospitals' Financial health in rural and urban areas in Poland: does it ensure sustainability? Sustainability 2019 11(7), Available at: https:// www.mdpi.com/2071-1050/11/7/1932/htm [Accessed June 22, 2020].

36. Guliani, H. Mix of maternity care providers in Canada. Healthcare Policy 2015; 11(1). Available at: http://www.longwoods.com/content/24384 [Accessed April 24, 2016].

37. Pilkington, $\mathrm{H}$. et al. Choice in maternity care: associations with unit supply, geographic accessibility and user characteristics. Int J Health Geographics 2012 11(1): 35. Available at: http://ij-healthgeographics.biomedcentral.com/ articles/10.1186/1476-072X-11-35 [Accessed April 24, 2016].

38. Committee on Fetus and Newborn. Levels of neonatal care. Pediatrics, 2012; 130(3): 587-597. Available at: http://pediatrics.aappublications.org/ content/130/3/587 [Accessed October 7, 2014].

39. Michalski G., et al. Can we determine debt to equity levels in non-profit organizations? Answer based on polish case. Eng Econ,2018; 29(5): 526-535. Available at: http://inzeko.ktu.lt/index.php/EE/article/view/19666 [Accessed June 22, 2020].

40. Palisano, R. et al. Development and reliability of a system to classify gross motor function in children with cerebral palsy. Develop Med Child Neurol 1997 39(4): 214-23. Available at: http://www.ncbi.nlm.nih.gov/pubmed/91 83258 [Accessed May 17, 2014].

41. Shi L. Health Services Research Methods. 2nd ed. Clifton Park: Thomson; 2008.

42. SOGO. Attendance at Labour and Delivery Guidelines for Obstetrical Care, Ottawa 2000.

43. Liston, R., Sawchuck, D. \& Young, D. Fetal health surveillance: antepartum and intrapartum consensus guideline. Journal of obstetrics and gynaecology Canada : JOGC 2007; 29(9 Suppl 4): S3-56. Available at: http:// www.ncbi.nlm.nih.gov/pubmed/17845745 [Accessed May 15, 2014].

44. Trønnes, H. et al. Risk of cerebral palsy in relation to pregnancy disorders and preterm birth: a national cohort study. Dev Med Child Neurol. 2014 Available at: http://www.ncbi.nlm.nih.gov/pubmed/24621110 [Accessed May 19, 2014].

45. Gavurova B. et al. Exploration of disparities in regions and specialized fields of day surgery system. Environ Res Public Health 2020; 17: 936. Available at : https://pubmed.ncbi.nlm.nih.gov/32028666/ [Accessed June 22, 2020].

46. Ministry of Health. 2014/2015 interprovincial reciprocal billing rates 2014 Victoria.

47. Johnston, K.M. et al. The economic burden of prematurity in Canada. BMC Pediatrics 2014 14(1), 93. Available at: http://bmcpediatr.biomedcentral.com/ articles/10.1186/1471-2431-14-93 [Accessed April 19, 2016].

48. Health Canada, Family-centred maternity and newborn care: national guidelines. Ottawa.

49. Kattwinkel, J. Textbook of Neonatal Resuscitation 5th ed., elk Grove Village, IL: of, Ed American Academy Association, pediatrics and American heart 2006.

50. Bang, A.T. et al.. Management of birth asphyxia in home deliveries in rural Gadchiroli: the effect of two types of birth attendants and of resuscitating with mouth-to-mouth, tube-mask or bag-mask. J Perinatol 200525 Suppl 1; S82-S91. Available at: http://www.ncbi.nlm.nih.gov/pubmed/15791282 [Accessed June 11, 2014].

51. Gill, C.J. et al. Effect of training traditional birth attendants on neonatal mortality (Lufwanyama neonatal survival project): randomised controlled study. BMJ (Clinical research ed.) 2011; 342: d346. Available at: http://www. pubmedcentral.nih.gov/articlerender.fcgi?artid=3032994\&tool= pmcentrez\&rendertype=abstract [Accessed June 11, 2014]. 
52. Lasswell, S.M. et al.. Perinatal regionalization for very low-birth-weight and very preterm infants: a meta-analysis. JAMA, 2010b; 304(9): 992-1000. Available at: http://www.ncbi.nlm.nih.gov/pubmed/20810377.

53. Bolbocean, C. et al.. Perinatal regionalization and implications for long-term health outcomes in cerebral palsy. Can J Neurol Sci 2016; 43(2): 248-253. Available at: http://www.ncbi.nlm.nih.gov/pubmed/26790470 [Accessed April 18, 2016].

\section{Publisher's Note}

Springer Nature remains neutral with regard to jurisdictional claims in published maps and institutional affiliations.

Ready to submit your research? Choose BMC and benefit from:

- fast, convenient online submission

- thorough peer review by experienced researchers in your field

- rapid publication on acceptance

- support for research data, including large and complex data types

- gold Open Access which fosters wider collaboration and increased citations

- maximum visibility for your research: over $100 \mathrm{M}$ website views per year

At BMC, research is always in progress.

Learn more biomedcentral.com/submissions 